\title{
Role of thermodynamic effect on coal-gas interactions during underground pre- and post- mining coal seams in the environmental geology
}

\author{
Tongqiang Xia Ph.D.
}

Xia TQ, Role of thermodynamic effect on coal-gas interactions during underground pre- and post- mining coal seams in the environmental geology. J Environ Geol. 2017;1(1): 7-8.

$\mathrm{U}$ nderground coal mining generally occurs in the terrifically thermodynamic environment of high geostress and geotherm, resulting in many coal-gas disasters, such as coal-gas outburst, coal spontaneous combustion and even gas explosion etc. (1-3). Geological statistics and relative researches show that when mining depth is over $1000 \mathrm{~m}$, the geotherm will reach the range of 40 and $45^{\circ} \mathrm{C}$ with the commonly geothermal gradient of $30-50^{\circ} \mathrm{C} / \mathrm{km}$, and the geostress is $95-135 \mathrm{MPa}$ at $3500-5000 \mathrm{~m}$ depth (4). In addition, the geotherm has a significant impact on geomechanics of coal-rock mass: the variation of $1{ }^{\circ} \mathrm{C}$ within the coal-rock medium may trigger the insitu stress change of 0.4-0.5 $\mathrm{MPa}$ (5).

Coal-gas disasters pose a difficult, persistent and costly problem for coal industries worldwide, usually causing huge economic losses, personal casualties, perilous land subsidence and massive environmental contamination (6-10). The fundamental understanding of gas migration and coal self-heating is essential to eliminate their dangers as mining hazards or develop the potential as an unconventional gas resource recovered (1114). The evolution of coal-gas interaction processes is a chain of physicochemical reactions in underground pre- and post- mining coal seams, which is labeled as "coupled processes" implying that one reaction process affects the initiation and progress of another (15-17). This reaction chain is linked together through dominant mechanisms, including compositional gas flow and diffusion, reaction kinetics, energy transport and coal deformation $(1,2,15)$. The individual reaction process, in the absence of full consideration of cross couplings, forms the basis of well-known disciplines such as hydrology, chemistry, elasticity and heat transfer $(1,15)$.

Advances in our understanding of coal-gas interactions have provided some effective measures to retard or suppress underground coal-gas disasters and enhance potential resource utilization quality. Some typically mathematical models had been established to reveal coupled hydro-mechanical mechanism of coal seam gas flow, such as Palmer-Mansoori model (18), Shi-Durucan model (19), Zhang-Liu model (17) and Xia-Zhou model $(20,21)$ etc., but failed to consider the influence of thermal effect on coal-gas interactions. However, in real coal mining environment, the thermodynamic effect may not only have a significant impact on the micro- and macro- structure evolution of coal-rock mass, but on gas ad/desorption, diffusion and migration behaviors. Thus, the thermodynamic effect should not be ignored in addressing the coal-gas interactions, which has become a kind of common recognition among many contemporary experts and scholars. Levy J et al. carried out an adsorption experiment of some coal sample, which showed that when the gas pressure of the coal sample was $5 \mathrm{MPa}$ and the temperature was the range of 20 and $65^{\circ} \mathrm{C}$, the adsorbed quantity of coal gas would be reduced by 0.12 $\mathrm{m}^{3} / \mathrm{t}$ as the temperature increased by $1^{\circ} \mathrm{C}(22)$. Yin GZ, et al. experimentally studied the influence of thermal effect on the total stress-strain and gas flow characteristics of gaseous coals under the conditions of constant gas pressure and confining pressure (23). Based on the experimental study of the relationship among the permeability, temperature and stress, $\mathrm{Li}$ $Z Q$, et al. revealed that the relationship between the permeability and the temperature of coal sample was not monotone increasing or decreasing, but had a transition point under different effective stress (24). According to the permeability experiment of raw coal under the different temperatures and effective stresses, Xu J, et al. found that the larger the effective stress was, the less sensitive the thermal effect was (25). He MC, et al. and Wang CG, et al. implemented gas adsorption and seepage experiment under the uniaxial stress and heating conditions, which showed the thermodynamic effect had a significant impact on the mechanism of coal deformation, gas ab/desorption and migration $(5,26)$. Peng SJ, et al. carried out the physical simulation test of gas extraction under different stress levels to study the evolution laws of coal temperature decline induced by gas desorption in extraction (27). Yang XL, et al. thought that the permeability of coal could be impressionable to some factors including effective stress, gas adsorption-induced microcalorimetry and coal temperature. Based on the experiment data, they further established a coupled hydro-mechanical model to address the characteristics of gas flow in coal seams (28). Taking the influence of thermodynamic effect on gas pressure, gas content, porosity and permeability into account. Li ZQ and Xian XF proposed a model of coal gas flow under the combined effects of the stress and temperature (29). Zhu et al. developed a coupled model of coal deformation, gas transport and thermal transport to examine the complex coal-gas interactions under variable temperatures (16). Considering the effects of gas pressure and gas desorption of coal. Tao YQ and Zhang LP established a coupled multi-physical model including temperature field, gas pressure field and coal deformation field Subsequently, they carried out different numerical simulations based on the enhanced gas recovery project of both energy and gas injections, respectively $(30,31)$. In our latest work, my collaborators and I developed a series of coal-gas interaction models including hydro-mechanical models $(20,21,32)$ and hydro-thermo-mechanical models $(2,3,10,11,13)$, through combining some key physico-chemical reactions together, such as coal-rock deformation (gas-ad/desorption- and temperatureinduced coal shrinking or swelling, and mining-induced coal-rock porosity evolution), methane diffusion from matrix, and compositional gas flow in fractures, coal-oxygen reaction kinetics, and thermal transport mechanisms, to further characterize gas migration or coal self-heating behaviors in underground coal seams or gobs.

Although a certain degree of success has been achieved using the above models and experiments to evaluate the coal gas or energy migration, control and recovery, the role of thermodynamic effect on coal-gas interactions during underground pre- and post- mining coal seams is not well understanding. This knowledge gap is likely to play a huge impact on coal-gas rick control and potential resource recovery. Thus, successful addressing the impact of thermodynamic effect on coal-gas interactions during underground pre- and post- mining coal seams will be serious scientific spotlights and challenges.

In this paper I have given a brief review of my research area associated with modern Environmental Geology. As we all known, unconventional coal resource and unconventional gas of shale and coal gas are causing a shift in the dynamics of the international energy structure, and there are a lot of similar issues and problems between coal and shale gas exploiting area. Because many scientific problems during unconventional gas and coal resource exploiting are closely related to multi-disciplines, including geoscience, rock mechanics, multi-component and multi-phase flow, geochemistry and thermodynamics

State Key Laboratory of Coal Resources and Safe Mining, China University of Mining and Technology, Xuzhou 221008, China

Correspondence: Tongqiang Xia Ph.D. Lecturer, State Key Laboratory of Coal Resources and Safe Mining, China University of Mining and Technology, Xuzhou 221008, China. Telephone +86 15062191329, e-mail tq.xia@cumt.edu.cn

Received: October 09, 2017, Accepted: October 12, 2017, Published: October 16, 2017

open $\bigcirc$ Access

This open-access article is distributed under the terms of the Creative Commons Attribution Non-Commercial License (CC BY-NC) (http:// creativecommons.org/licenses/by-nc/4.0/), which permits reuse, distribution and reproduction of the article, provided that the original work is properly cited and the reuse is restricted to noncommercial purposes. For commercial reuse, contact reprints@pulsus.com 
etc., which is consistent with our theme of journal, I think that the journal "Environmental Geology" should give and be a great place to focus on this research area.

\section{ACKNOWLEDGEMENTS}

This work was supported by the National Science Foundation of China (51604269), Postdoctoral Science Foundation funded project of China (2017T100415), and Open Projects of State Key Laboratory of Coal Resources and Safe Mining (SKL-CRSM16KFD06).

\section{REFERENCES}

1. Song ZY, Kuenzer C. Coal fires in China over the lastdecade: A comprehensive review. Int J Coal Geol 2014;133:72-99.

2. Xia TQ, Zhou FB, Gao F, et al. Simulation of coalself-heating processes in underground methane-rich coalseams. Int J Coal Geol 2015:141-142,1-12.

3. Xia TQ, Wang X.X, Zhou FB, et al. Evolution of coal self-heating processes in longwall gob areas. Int. J. Heat MassTransfer 2015;86:861-68.

4. Xie HP, Gao F, Ju Y. Research and development of rock mechanics in deep ground engineering. Chinese J Rock Mech Engin 2015;34(11):2161-78.

5. He MC, Wang CG, Li DJ, et al. Desorption characteristics of adsorbed gas in coal samples under coupling temperature and uniaxial compression. Chinese. J Rock Mech Engin 2010;29(5):865-72.

6. An F, Cheng Y, Wang L, et al. A numerical model for outburst including the effect of adsorbed gas on coal deformation and mechanical properties. Comput. Geotech 2013;54:222-231.

7. Carras JN, Young BC. Self-heating of coal and related materials: models, application and test methods. Prog Energy Combust 1994;20:1-15.

8. Guo H, Yuan L, Shen B, et al. Mining-induced stratastress changes, fractures and gas flow dynamics inmulti-seam longwall mining. Int J Rock Mech Min Sci 2012;54:129-39.

9. Kuenzer C, Zhang, J, Tetzlaff A, et al. Uncontrolled coal fires and their environmental impacts: investigating two arid mining regions in northcentral China. Appl. Geogr 2007;27:42-62.

10. Xia TQ, Wang XX, Zhou FB, et al. Evolution of coal self-heating processes in longwall gob areas. Int J Heat Mass Tran 2015;86:861-68.

11. Xia TQ, Zhou FB, Wang XX, et al. Safety evaluation of combustion-prone long wall mining gobs induced by gas extraction: a simulation study. Process Saf Environ Prot 2017;109: 677-87.

12. Zhou FB, Xia TQ, Wang XX, et al. Recent developments in coal mine methane extraction and utilization in China: a review. J Nat Gas Sci Eng 31, $437-458$

13. Xia TQ, Zhou FB, Wang XX, et al. Controlling factors of symbiotic disaster between coal gas and spontaneous combustion in long wall mining gobs. Fuel 2016;182:886-96.

14. Liu J, Chen Z, Elsworth D, et al. Evaluation of stress-controlled coal swelling processes. Int J Coal Geol 2010;83:446-55.

15. Liu J, Chen Z, Elsworth D, et al. Interactions of multiple processes during CBM extraction: a critical review. Int J Coal Geol 2011;87:175-89.
16. Zhu W, Wei C, Liu J, et al. A model of coal-gas interaction under variable temperatures. Int J Coal Geol 2011;86:213-21.

17. Zhang H, Liu J, Elsworth D. How sorption-induced matrix deformation affects gas flow in coal seams: a new FE model. Int J Rock Mech Min 2008;45:1226-36.

18. Palmer I, Mansoori J. How permeability depends on stress and pore pressure in coalbeds: A new model. Paper SPE 52607. SPE Reservoir Eval Eng (December) 1998:539-44.

19. Shi JQ, Durucan S. Changes in permeability of coalbeds during primary recovery. Part 1. Model Formulation and Analysis. Paper 0341. In: Proceedings of the 2003 International Coalbed Methane Symposium, University of Alabama, Tuscaloosa, Alabama, May.20. Xia TQ, Zhou FB, Liu J, et al. Evaluation of the pre-drained coal seam gas quality. Fuel 2014;130:296-305.

21. Xia TQ, Zhou FB, Liu J, et al. A fully coupled coal deformation and compositional flow model for the control of the pre-mining coal seam gas extraction. Int J Rock Mech Min 2014;72:138-48.

22. Levy J, Day SJ, Killingley JS. Methane capacity of Bowen Basin coals related to coal properties. Fuel 1997;74:1-7.

23. Yin GZ, Jiang CB, Xu J, et al. Experimental study of thermos-fluid solid coupling seepage of coal containing gas. J of China Coal Soci 2011;36(9):1495-1500.

24. Li ZQ, Xian XF, Long QM, et al. Experiment study of coal permeability under different temperature and stress. J of China $U$ of Min Techn 2009;38(4):524-26.

25. Xu J, Zhang DD, Peng SJ, et al. Experimental research on impact of temperature on seepage characteristics of coal containing methane under triaxial stress. Chinese J of Rock Mech Engin 2011;30(9):1849-53.

26. Wang CG, Chen LJ, Wang CS, et al. Experiment on thermal-induced expansion and mechanical properties of gas-bearing intact coal subjected to thermal-mechanical loading. Rock Soil Mechan 2014;35(4):1015-24.

27. Peng SJ, Zhang CL, Xu J, et al. Physical simulation experiment on the evolution of temperature during CBM drainage. Chinese J of Rock Mech Engin 2015;34(7):1325-33.

28. Yang XL, Zhang YL, Li CQ, et al. Experimental study on desorption and seepage rules of coal-bed gas considering temperature conditions. Chinese J of Geotecn Eng 2008;30(12):1811-14.

29. Li ZQ, Xian XF. Study on experiment of coal permeability with temperature and stress changing. J of Liaoning Techn 2009;28:156-59.

30. Tao YQ, Xu J, Cheng MJ, et al. Theoretical analysis and experimental study on permeability of gas-bearing coal. Chinese J of Rock Mech Engin 2009;28:3363-70.

31. Zhang LP. Mechanism of coupled thermal-hydrologic-mechanical processes for exploiting coal bed methane in low permeability reservoir and its applications. Ph.D. Dissertation, China University of Mining and Technology, Xuzhou, China. 2011.

32. Xia TQ, Xu MJ, Wang YL. Simulation investigation on flow behavior of gob gas by applying a newly developed FE software. Environ Earth Sci 2017;76:485 